\title{
Incidence and Risk Factors of Chronic Pulmonary Aspergillosis Development during Long-Term Follow-Up after Lung Cancer Surgery
}

\author{
Sun Hye Shin ${ }^{1,+}$, Bo-Guen Kim ${ }^{1,+} \mathbb{C}^{\mathbb{C}}$, Jiyeon Kang ${ }^{2}$, Sang-Won Um ${ }^{1}$, Hojoong Kim ${ }^{1}{ }^{\mathbb{D}}$, \\ Hong Kwan Kim ${ }^{3}{ }^{1}$, Jhingook Kim ${ }^{3}$, Young Mog Shim ${ }^{3}$, Yong Soo Choi ${ }^{3, *} \ddagger$ and \\ Byeong-Ho Jeong $1, *, \ddagger$ D \\ 1 Division of Pulmonary and Critical Care Medicine, Department of Medicine, Samsung Medical Center, \\ Sungkyunkwan University School of Medicine, Irwon-ro 81, Gangnam-gu, Seoul 06351, Korea; \\ freshsunhye@gmail.com (S.H.S.); kbg1q2w3e@gmail.com (B.-G.K.); sangwonum@skku.edu (S.-W.U.); \\ hjk3425@skku.edu (H.K.) \\ 2 Department of Pulmonology, Inje University Seoul Paik Hospital, Seoul 04551, Korea; qsrsr52@naver.com \\ 3 Samsung Medical Center, Department of Thoracic Surgery, Sungkyunkwan University School of Medicine, \\ Irwon-ro 81, Gangnam-gu, Seoul 06351, Korea; hkts@skku.edu (H.K.K.); jhingookkim@gmail.com (J.K.); \\ ymshim@skku.edu (Y.M.S.) \\ * Correspondence: choi.smcts@gmail.com (Y.S.C.); myacousticlung@gmail.com (B.-H.J.); \\ Tel.: (+82)-02-3410-6542 (Y.S.C.); (+82)-02-3410-3429 (B.-H.J.); \\ Fax: (+82)-02-3410-6986 (Y.S.C.); (+82)-02-3410-3849 (B.-H.J.) \\ + Co-first author. \\ $\ddagger$ These authors contributed equally to this work.
}

Received: 11 October 2020; Accepted: 7 November 2020; Published: 9 November 2020

check for updates

\begin{abstract}
Lung resection surgery for non-small-cell lung cancer (NSCLC) is reportedly a risk factor for developing chronic pulmonary aspergillosis (CPA). However, limited data are available regarding the development of CPA during long-term follow-up after lung cancer surgery. This study aimed to investigate the cumulative incidence and clinical factors associated with CPA development after lung cancer surgery. We retrospectively analyzed 3423 patients with NSCLC who (1) underwent surgical resection and (2) did not have CPA at the time of surgery between January 2010 and December 2013. The diagnosis of CPA was based on clinical symptoms, serological or microbiological evidences, compatible radiological findings, and exclusion of alternative diagnoses. The cumulative incidence of CPA and overall survival (OS) were estimated using the Kaplan-Meier method, and a multivariable Cox proportional hazard analysis was performed to identify factors associated with CPA development. Patients were followed-up for a median of 5.83 years with a 72.3\% 5-year OS rate. Fifty-six patients developed CPA at a median of 2.68 years after surgery, with cumulative incidences of $0.4 \%, 1.1 \%, 1.6 \%$, and $3.5 \%$ at $1,3,5$, and 10 years, respectively. Lower body mass index (BMI), smoking, underlying interstitial lung disease, thoracotomy, development of postoperative pulmonary complications 30 days after surgery, and treatment with both chemotherapy and radiotherapy were independently associated with CPA development. The cumulative incidence of CPA after surgery was 3.5\% at 10 years and showed a steadily increasing trend during long-term follow-up. Therefore, increased awareness regarding CPA development is needed especially in patients with risk factors.
\end{abstract}

Keywords: chronic pulmonary aspergillosis; lung cancer; surgery

\section{Introduction}

Surgical resection remains the mainstay of curative treatment for non-small-cell lung cancer (NSCLC) [1]. The implementation of low-dose computed tomography (CT) screening has made it 
possible to diagnose more patients at resectable stages of the disease [2,3]. Additionally, the past few decades saw significant advances in clinical staging and surgical techniques $[4,5]$. As a result, patients now have a favorable prognosis after surgical resection for NSCLC [6,7].

However, lung cancer surgery is one of the most invasive procedures in medicine and carries considerable risks for developing postoperative pulmonary complications (PPCs) such as pneumonia, empyema, and mediastinitis [8]. While these infectious PPCs mostly occur within 30 or 90 days after surgery $[9,10]$, the impact of the operation may persist beyond the immediate postoperative period and may predispose patients to develop chronic pulmonary infections.

Chronic pulmonary aspergillosis (CPA) is an uncommon but detrimental pulmonary disease caused by members of the genus Aspergillus [11] that usually develops in patients with pre-existing pulmonary disease such as tuberculosis (TB) [12-14]. A history of treatment for lung cancer or thoracic surgery has been reported as an underlying condition that predisposes patients to CPA [13]. However, there are limited data regarding the development of CPA during long-term follow-up after lung cancer surgery [15].

This study aimed to determine the cumulative incidence of CPA after lung cancer surgery by analyzing a large cohort of patients who complied with long-term follow-up after surgical resection for NSCLC. Furthermore, we also investigated which clinical factors were associated with the development of CPA.

\section{Methods}

\subsection{Study Population and Data Collection}

Patients with NSCLC who underwent surgical resection between January 2010 and December 2014 were identified retrospectively using the Lung Cancer Surgery Registry at Samsung Medical Center, a 1979-bed referral hospital in Seoul, Korea. Patients with a concurrent diagnosis of CPA at the time of surgery were excluded.

The following information was then gathered using the database: patient-related factors such as age, sex, body mass index (BMI), smoking history, underlying pulmonary diseases, and other comorbidities; lung cancer-related factors such as the lobar location of the tumor and the clinical/pathological stage of the disease; and treatment-related factors such as the neoadjuvant treatment used, the extent of surgical resection, the surgical approach, PPCs, and adjuvant treatments administered. Conditions considered as underlying pulmonary disease included a previous history of pulmonary $\mathrm{TB}$, chronic obstructive pulmonary disease (COPD), asthma, or interstitial lung disease (ILD). Tumor stages were determined using the seventh edition of the American Joint Committee on Cancer [16]. Early PPC was defined as the development of pneumonia, acute respiratory distress syndrome or respiratory failure, significant atelectasis requiring bronchoscopy or reintubation, pleural effusion, bronchopleural fistula, empyema, prolonged air leakage lasting for more than 5 days, or pneumothorax during the patient's hospital stay or during readmission within 30 days after surgery. Late PPC was defined as the development of the same complications more than 30 days after the surgery [17].

This study was approved by the Institutional Review Board of Samsung Medical Center (IRB no. 2020-06-011). The requirement for informed consent was waived owing to its retrospective nature.

\subsection{Diagnosis of CPA}

After surgical resection for NSCLC, most patients were followed-up for at least 5 years by a thoracic surgeon. Patients with pre-existing or newly developed pulmonary disease were jointly followed-up by a pulmonologist. Physical examinations, laboratory tests, chest radiographies, and chest CT scans were regularly performed at scheduled intervals during follow-up visits. When the development of CPA was suspected, patients were referred to a pulmonologist, and further diagnostic tests were performed. The diagnosis of CPA was established on the basis of (1) the presence of compatible clinical symptoms; (2) serological or microbiological evidence of Aspergillus infection, including positive serum 
Aspergillus precipitin tests (Aspergillus fumigatus Immunoglobulin G Enzyme-linked Immunosorbent Assay kit; IBL International, Hamburg, Germany) and isolation of Aspergillus spp. from respiratory specimens, or histological confirmation; (3) radiological findings compatible with evidence of disease progression; and (4) exclusion of alternative diagnoses, according to the widely accepted diagnostic criteria proposed by European Society for Clinical Microbiology and Infectious Diseases/European Respiratory Society $[11,18]$.

\subsection{Statistical Analyses}

Categorical variables are reported as number (\%), while continuous variables are reported as median (interquartile range (IQR)). Patients who developed CPA were compared to those who did not develop CPA by using the Pearson $\chi^{2}$ test or Fisher's exact test for categorical variables and the Mann-Whitney test for continuous variables. The Kaplan-Meier method was used to estimate the cumulative incidence of CPA and overall survival (OS) after the surgery. The data of patients who were (1) alive and did not develop CPA, (2) lost to follow-up, and (3) deceased were censored at their last visit to the clinic to analyze the incidence of CPA. For the analysis of OS, the data of patients who were alive or lost to follow-up were censored at the time they were last known to be alive regardless of whether or not they developed CPA.

We used the Cox proportional hazard model to calculate hazard ratios (HRs) and 95\% confidence intervals (CIs) for the development of CPA. We entered all relevant variables into the multivariable model and eliminated variables using a stepwise backward selection method $(p<0.05$ for entry and $p>0.10$ for removal). Tumor stages were not included in the multivariable model since they had a significant collinearity with neoadjuvant and adjuvant treatments. All tests were two-sided, and a $p$ value $<0.05$ was considered significant. Predictive Analytics Software (PASW) Statistics 25 (SPSS Inc., Chicago, IL, USA) was used for analysis.

\section{Results}

\subsection{Study Population and Overall Survival}

Out of 3430 patients who underwent surgical resection for NSCLC, seven were diagnosed with CPA by the time of the surgery and excluded from this study (Figure 1). As shown in Table 1, the median age of the study population was 63 years (IQR, 56-69 yeas) and 63.6\% were male. The majority of the patients $(60.8 \%)$ were either current or previous smokers. Video-assisted thoracoscopic surgery (VATS) was performed in $59.4 \%$ of the cases (Table 2). Lobectomy was the most common procedure performed $(77.0 \%)$ followed by sublobar resection $(14.4 \%)$, bilobectomy $(4.5 \%)$, and pneumectomy $(4.1 \%)$.

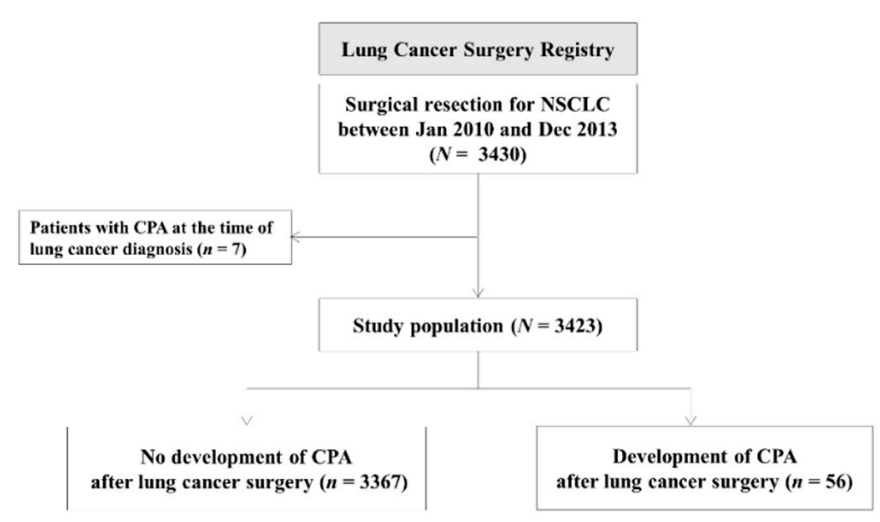

Figure 1. Selection of the study population. NSCLC, non-small-cell lung cancer; CPA, chronic pulmonary aspergillosis. 
Table 1. Baseline characteristics of patients with NSCLC and the development of chronic pulmonary aspergillosis after lung resection.

\begin{tabular}{|c|c|c|c|c|c|}
\hline Variables & $\begin{array}{c}\text { Total } \\
(n=3423)\end{array}$ & $\begin{array}{c}\text { CPA (-) } \\
(n=3367)\end{array}$ & $\begin{array}{l}\text { CPA (+) } \\
(n=56)\end{array}$ & $p$-Value & $\begin{array}{c}\text { CPA Incidence } \\
(\%)\end{array}$ \\
\hline Age, years & $63(56-69)$ & $63(56-69)$ & $63(54-69)$ & 0.789 & - \\
\hline Sex, male & $2178(63.6)$ & $2131(63.3)$ & $47(83.9)$ & 0.001 & $47 / 2178(2.2)$ \\
\hline Smoking status & & & & $<0.001$ & \\
\hline Never smoker & $1343(39.2)$ & $1334(39.6)$ & $9(16.1)$ & & 9/1343 (0.7) \\
\hline Ex-smoker & $1060(31.0)$ & 1035 (30.7) & $25(44.6)$ & & 25/1060 (2.4) \\
\hline Current smoker & $1020(29.8)$ & 998 (29.6) & $22(39.3)$ & & $22 / 1020(2.2)$ \\
\hline Pack-years $(n=2080)$ & $35(20-50)$ & $35(20-50)$ & $40(30-60)$ & 0.059 & - \\
\hline BMI, $\mathrm{kg} / \mathrm{m}^{2}$ & $23.8(21.8-25.7)$ & $23.8(21.9-25.7)$ & $22.1(20.5-23.5)$ & $<0.001$ & - \\
\hline Comorbidity & & & & & \\
\hline \multicolumn{6}{|l|}{ Underlying pulmonary disease } \\
\hline History of pulmonary TB & $385(11.2)$ & $376(11.2)$ & $9(16.1)$ & 0.249 & 9/385 (2.3) \\
\hline COPD/Asthma & $1158(33.8)$ & $1140(33.9)$ & $18(32.1)$ & 0.788 & $18 / 1158(1.6)$ \\
\hline Interstitial lung disease & $44(1.3)$ & $42(1.2)$ & $2(3.6)$ & 0.161 & $2 / 44(4.5)$ \\
\hline $\mathrm{DM}$ & $560(16.4)$ & $550(16.3)$ & $10(17.9)$ & 0.760 & $10 / 560(1.8)$ \\
\hline Chronic heart disease & $213(6.2)$ & $209(6.2)$ & $4(7.1)$ & 0.777 & $4 / 213(1.9)$ \\
\hline Chronic renal disease & $31(0.9)$ & $31(0.9)$ & $0(0.0)$ & 1.000 & $0 / 31(0.0)$ \\
\hline Cerebrovascular disease & $144(4.2)$ & $143(4.2)$ & $1(1.8)$ & 0.731 & $1 / 144(0.7)$ \\
\hline Previous history of malignancy & $479(14.0)$ & $470(14.0)$ & $9(16.1)$ & 0.651 & $9 / 479(1.9)$ \\
\hline Clinical stage at diagnosis & & & & $<0.001$ & \\
\hline Stage I & $2254(65.8)$ & $2236(66.4)$ & $18(32.1)$ & & $18 / 2254(0.8)$ \\
\hline Stage II & $611(17.8)$ & $601(17.8)$ & $10(17.9)$ & & $10 / 611(1.6)$ \\
\hline Stage III & $514(15.0)$ & $487(14.5)$ & $27(48.2)$ & & $27 / 514(5.3)$ \\
\hline Stage IV & $44(1.3)$ & $43(1.3)$ & $1(1.8)$ & & $1 / 44(2.3)$ \\
\hline Tumor histology & & & & 0.007 & \\
\hline Adenocarcinoma & $2317(67.7)$ & $2290(68.0)$ & $27(48.2)$ & & $27 / 2317(1.2)$ \\
\hline Squamous cell carcinoma & $866(25.3)$ & $843(25.0)$ & $23(41.1)$ & & $23 / 866(2.7)$ \\
\hline Others ${ }^{*}$ & $240(7.0)$ & $234(6.9)$ & $6(10.7)$ & & $6 / 240(2.5)$ \\
\hline Location of lung cancer & & & & 0.213 & \\
\hline Right & $1990(58.1)$ & 1962 (58.3) & $28(50.0)$ & & 28/1990 (1.4) \\
\hline Left & 1433 (41.9) & 1405 (41.7) & $28(50.0)$ & & 28/1433 (2.0) \\
\hline
\end{tabular}

Data are presented as $n(\%)$ or the median (interquartile range). NSCLC, non-small cell lung cancer; CPA, chronic pulmonary aspergillosis; BMI, body mass index; TB, tuberculosis; COPD, chronic obstructive pulmonary disease; DM, diabetes mellitus. ${ }^{*}$ Includes large cell neuroendocrine carcinoma, adenosquamous carcinoma, pleomorphic carcinoma, adenoid cystic carcinoma, mucoepidermoid carcinoma, epithelial myoepithelial carcinoma, and carcinoid tumors.

Table 2. Treatment profile for NSCLC and the development of chronic pulmonary aspergillosis after lung resection.

\begin{tabular}{|c|c|c|c|c|c|}
\hline Variables & $\begin{array}{c}\text { Total } \\
(n=3423)\end{array}$ & $\begin{array}{c}\text { CPA (-) } \\
(n=3367)\end{array}$ & $\begin{array}{l}\text { CPA (+) } \\
(n=56)\end{array}$ & $p$-Value & $\begin{array}{c}\text { CPA Incidence } \\
(\%)\end{array}$ \\
\hline Neoadjuvant treatment & & & & $<0.001$ & \\
\hline No & 3067 (89.6) & $3032(90.1)$ & 35 (62.5) & & 35/3067 (1.1) \\
\hline Yes & $356(10.4)$ & $335(9.9)$ & $21(37.5)$ & & $21 / 356(5.9)$ \\
\hline CCRT & $299(8.7)$ & $279(8.3)$ & $20(35.7)$ & $<0.001$ & $20 / 299(6.7)$ \\
\hline Chemotherapy & $54(1.6)$ & $53(1.6)$ & $1(1.8)$ & 0.593 & $1 / 54(1.9)$ \\
\hline Radiotherapy & $3(0.1)$ & $3(0.1)$ & $0(0.0)$ & 1.000 & $0 / 3(0.0)$ \\
\hline Surgical approach & & & & $<0.001$ & \\
\hline VATS & $2033(59.4)$ & $2027(60.2)$ & $6(10.7)$ & & $6 / 2033(0.3)$ \\
\hline Thoracotomy & $1390(40.6)$ & $1340(39.8)$ & $50(89.3)$ & & $50 / 1390(3.6)$ \\
\hline Types of surgical resection & & & & 0.287 & \\
\hline Sublobar resection & $492(14.4)$ & $488(14.5)$ & $4(7.1)$ & & $4 / 492(0.8)$ \\
\hline Wedge resection & $349(10.2)$ & $346(10.3)$ & $3(5.4)$ & 0.228 & $3 / 349(0.9)$ \\
\hline Segmentectomy & $143(4.2)$ & $142(4.2)$ & $1(1.8)$ & 0.730 & $1 / 143(0.7)$ \\
\hline Lobectomy & $2637(77.0)$ & $2591(77.0)$ & $46(82.1)$ & & $46 / 2637(1.7)$ \\
\hline Bilobectomy & $153(4.5)$ & $148(4.4)$ & $5(8.9)$ & & $5 / 153(3.3)$ \\
\hline Pneumonectomy & $141(4.1)$ & $140(4.2)$ & $1(1.8)$ & & $1 / 141(0.7)$ \\
\hline
\end{tabular}


Table 2. Cont.

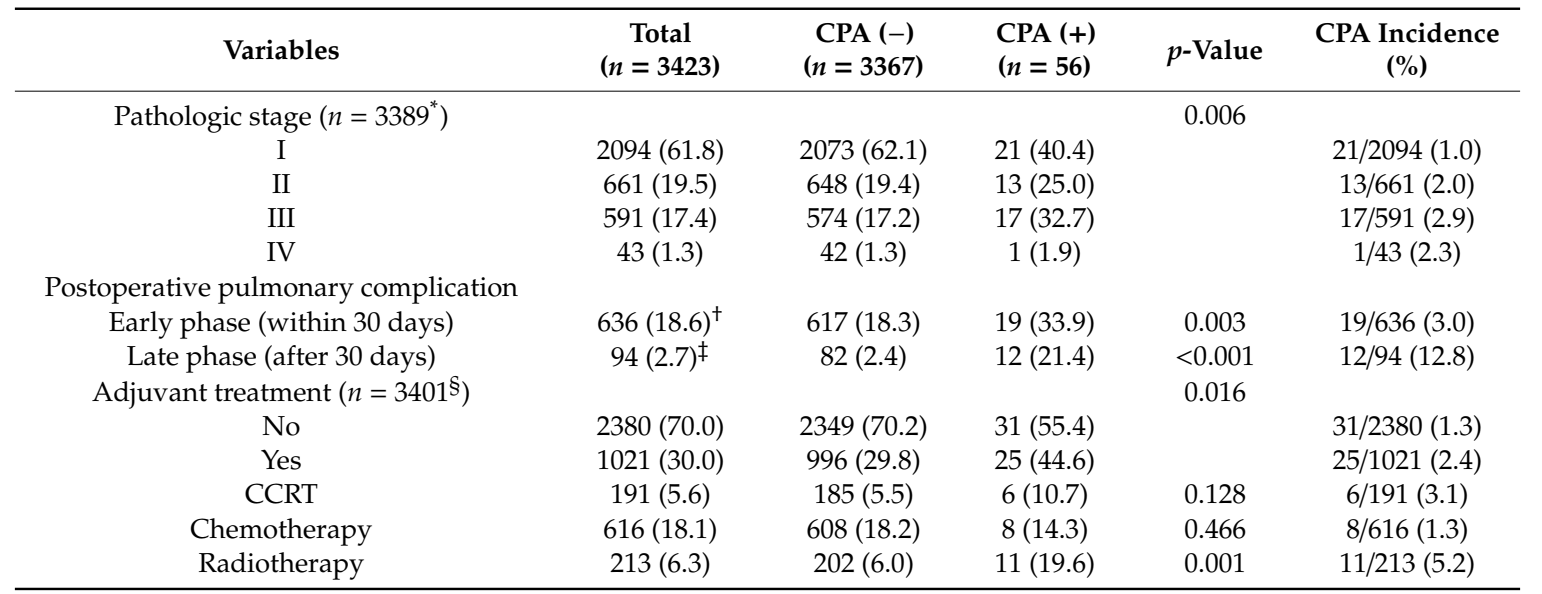

Data are presented as $n$ (\%). NSCLC, non-small cell lung cancer; CPA, chronic pulmonary aspergillosis; CCRT, concurrent chemoradiotherapy; VATS, video-assisted thoracoscopic surgery. *Except for 34 patients in whom no residual tumors appeared in the surgical specimen after neoadjuvant treatment (pathologic complete response (ypCR)). +Pneumothorax/prolonged air leak $(n=312)$, respiratory failure requiring mechanical ventilation $(n=137)$, pneumonia $(n=128)$, bronchopleural fistula $(n=20)$, others (atelectasis, pleural effusion, etc.) $(n=244)$. Some patients exhibited more than one complication. $\ddagger$ Pneumonia $(n=54)$, respiratory failure requiring mechanical ventilation $(n=25)$, pneumothorax/prolonged air leak $(n=15)$, bronchopleural fistula $(n=15)$, others (atelectasis, pleural effusion, etc.) $(n=31)$. Some patients exhibited more than one complication. §Excluded 22 patients due to data unavailability.

Patients were followed-up for a median of 5.83 (IQR, 2.92-7.25) years to assess survival, and the 5-year survival rate was 72.3\% (Figure 2A).

A

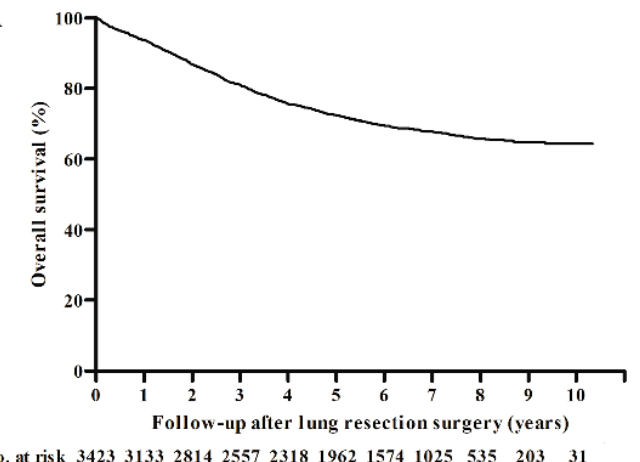

B

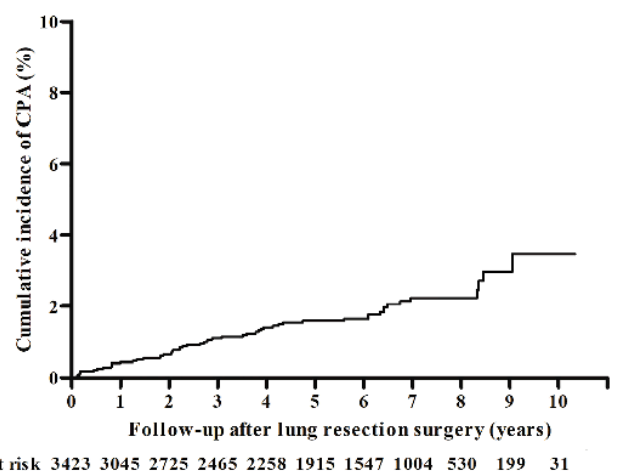

Figure 2. (A) Overall survival of the study population and (B) cumulative incidence of chronic pulmonary aspergillosis after lung cancer surgery.

\subsection{Development of CPA after Lung Cancer Surgery}

During the follow-up period, 56 patients developed CPA at a median of 2.68 (IQR, 1.07-4.53) years after their surgery. The cumulative incidences were $0.4 \%, 1.1 \%, 1.6 \%$, and $3.5 \%$ at $1,3,5$, and 10 years, respectively (Figure 2B). Most cases (44/56, 78.6\%) involved the ipsilateral side of the resected lung, followed by contralateral $(8 / 56,14.3 \%)$ and bilateral $(4 / 56,7.1 \%)$ development.

Patients who developed CPA were more likely to be male $(83.9 \%$ vs. $63.3 \%, p=0.001)$, smokers $(83.9 \%$ vs. $60.3 \%, p<0.001)$, and have lower BMI $\left(22.1 \mathrm{vs.} 23.8 \mathrm{~kg} / \mathrm{m}^{2}, p<0.001\right)$ than those who did not develop the disease. The presence of pre-existing pulmonary diseases, including history of pulmonary TB, COPD, asthma, and ILD, was not statistically different for the development of CPA. Patients who developed CPA were more likely to have advanced clinical stages of NSCLC (stage III and IV; $50.0 \%$ vs. $15.7 \%, p<0.001)$ and a histologic diagnosis of squamous cell carcinoma $(41.1 \%$ vs. $25.0 \%, p=0.007$ ) (Table 1). Accordingly, a greater percentage of patients who eventually developed CPA received neoadjuvant $(37.5 \%$ vs. $9.9 \%, p<0.001)$ and adjuvant $(44.6 \%$ vs. $29.8 \%, p=0.016)$ therapy than 
that of patients who did not develop the disease. Regarding surgical procedures, the rate of thoracotomies performed was markedly higher in the group that developed CPA than in the group that did not develop the disease $(89.3 \%$ vs. $39.8 \%, p<0.001)$. Both early $(33.9 \%$ vs. $18.3 \%, p=0.003)$ and late-phase $(21.4 \%$ vs. $2.4 \%, p<0.001$ ) PPC were more prevalent in the group that developed CPA (Table 2).

\subsection{Factors Associated with the Development of CPA}

To investigate which factors are independently associated with the development of CPA, both univariable and multivariable analyses were performed (Table 3). Lower BMI (adjusted HR (aHR) per $1 \mathrm{~kg} / \mathrm{m}^{2}$ increase, 0.83; 95\% CI, 0.76-0.91; $p<0.001$ ), smoking (aHR, 2.42; 95\% CI, 1.16-5.07; $p=0.019)$, underlying ILD (aHR, 5.80; 95\% CI, 1.35-25.00; $p=0.018)$, thoracotomy (aHR, 9.60; 95\% CI, 3.86-23.85; $p<0.001)$, late-phase PPC (aHR, 6.75; 95\% CI, 3.49-13.04; $p<0.001)$, and treatment with both chemotherapy and radiotherapy $(\mathrm{aHR}, 2.47 ; 95 \% \mathrm{CI}, 1.33-4.58 ; p=0.004)$ were all associated with the development of CPA.

Table 3. Prognostic factors associated with the development of chronic pulmonary aspergillosis after lung resection for NSCLC $(n=3423)$.

\begin{tabular}{|c|c|c|c|c|}
\hline \multirow[b]{2}{*}{ Variables } & \multicolumn{2}{|c|}{ Univariable Cox Regression } & \multicolumn{2}{|c|}{ Multivariable Cox Regression } \\
\hline & $\begin{array}{c}\text { Unadjusted HR } \\
(95 \% \mathrm{CI})\end{array}$ & $p$-Value & $\begin{array}{c}\text { Adjusted HR } \\
(95 \% \mathrm{CI})\end{array}$ & $p$-Value \\
\hline \multicolumn{5}{|l|}{ Host-related factors } \\
\hline Age, years & $1.01(0.98-1.04)$ & 0.524 & & \\
\hline Sex, male & $3.73(1.83-7.62)$ & $<0.001$ & & \\
\hline Body mass index, $\mathrm{kg} / \mathrm{m}^{2}$ & $0.82(0.74-0.90)$ & $<0.001$ & $0.83(0.76-0.91)$ & $<0.001$ \\
\hline \multicolumn{5}{|l|}{ Smoking history } \\
\hline No & Reference & & Reference & \\
\hline Yes & $4.25(2.08-8.67)$ & $<0.001$ & $2.42(1.16-5.07)$ & 0.019 \\
\hline \multicolumn{5}{|l|}{ Comorbidity } \\
\hline Previous history of pulmonary tuberculosis & $1.56(0.76-3.17)$ & 0.225 & & \\
\hline COPD/Asthma & $0.95(0.54-1.66)$ & 0.854 & & \\
\hline Interstitial lung disease & $5.99(1.45-24.71)$ & 0.013 & $5.80(1.35-25.00)$ & 0.018 \\
\hline Diabetes mellitus & $1.30(0.66-2.57)$ & 0.456 & & \\
\hline Previous history of malignancy & $1.19(0.59-2.43)$ & 0.627 & $1.98(0.94-4.19)$ & 0.073 \\
\hline \multicolumn{5}{|l|}{ Cancer-related factors } \\
\hline \multicolumn{5}{|l|}{ Tumor histology } \\
\hline Adenocarcinoma & Reference & & & \\
\hline Squamous cell carcinoma & $3.10(1.77-5.42)$ & $<0.001$ & & \\
\hline Others $^{*}$ & $2.95(1.22-7.15)$ & 0.017 & & \\
\hline \multicolumn{5}{|l|}{ Treatment-related factors } \\
\hline \multicolumn{5}{|l|}{ Surgical approach } \\
\hline VATS & Reference & & Reference & \\
\hline Thoracotomy & $16.69(7.15-38.96)$ & $<0.001$ & $9.60(3.86-23.85)$ & $<0.001$ \\
\hline \multicolumn{5}{|l|}{ Types of Surgical resection } \\
\hline Lobectomy & Reference & & & \\
\hline Sublobar resection & $0.45(0.16-1.24)$ & 0.123 & & \\
\hline Bilobectomy & $2.22(0.88-5.60)$ & 0.090 & & \\
\hline Pneumonectomy & $0.65(0.09-4.68)$ & 0.664 & & \\
\hline \multicolumn{5}{|l|}{ Postoperative pulmonary complication } \\
\hline Early phase (within 30 days) ${ }^{\dagger}$ & $2.69(1.54-4.67)$ & $<0.001$ & & \\
\hline Late phase (after 30 days) $\ddagger$ & $14.60(7.70-27.69)$ & $<0.001$ & $6.75(3.49-13.04)$ & $<0.001$ \\
\hline \multicolumn{5}{|l|}{ Neoadjuvant or Adjuvant treatment } \\
\hline No & Reference & & Reference & \\
\hline Chemotherapy only & $0.84(0.32-2.20)$ & 0.723 & $0.43(0.16-1.14)$ & 0.088 \\
\hline Radiotherapy only & $4.31(1.02-18.25)$ & 0.047 & $1.47(0.34-6.37)$ & 0.604 \\
\hline Chemotherapy and radiotherapy both & $5.93(3.38-10.40)$ & $<0.001$ & $2.47(1.33-4.58)$ & 0.004 \\
\hline
\end{tabular}

NSCLC, non-small cell lung cancer; HR, hazard ratio; CI, confidential interval; BMI, body mass index; COPD, chronic obstructive pulmonary disease; VATS, video-assisted thoracoscopic surgery. *Includes large cell neuroendocrine carcinoma, adenosquamous carcinoma, pleomorphic carcinoma, adenoid cystic carcinoma, mucoepidermoid carcinoma, epithelial myoepithelial carcinoma, and carcinoid tumors. +Pneumothorax/prolonged air leak $(n=312)$, respiratory failure requiring mechanical ventilation $(n=137)$, pneumonia $(n=128)$, bronchopleural fistula $(n=20)$, others (atelectasis, pleural effusion, etc.) $(n=244)$. Some patients exhibited more than one complication. $\ddagger$ Pneumonia $(n=54)$, respiratory failure requiring mechanical ventilation $(n=25)$, pneumothorax/prolonged air leak $(n=15)$, bronchopleural fistula $(n=15)$, others (atelectasis, pleural effusion, etc.) $(n=31)$. Some patients exhibited more than one complication. 


\section{Discussion}

In the present study, patients with NSCLC who underwent surgical resection showed a favorable prognosis with a 5-year survival rate of 72.3\%. During long-term follow-up, a small number of patients developed CPA, with a 10-year cumulative incidence of 3.5\%. However, the incidence of CPA did not plateau and continued to increase many years following surgery; this suggests that CPA is an important late complication of lung surgery. We also found that factors such as lower BMI, smoking, underlying ILD, and thoracotomy, as well as PPC after 30 days and neoadjuvant/adjuvant therapy with both chemotherapy and radiotherapy, were all independently associated with CPA development.

CPA often develops in patients with pre-existing structural changes of the lung. Pulmonary TB typically leaves cavitation in the lung and has been reported as the most common underlying condition in CPA development; worldwide, an estimated 1.2 million people with CPA have a history of pulmonary TB $[12,13]$. A recent study has found that CPA complicates $26 \%$ of patients who were previously treated for TB and were left with residual pulmonary cavities [14]. Likewise, surgical resection impacts the physical structure of the lung and has been suggested as a risk factor of CPA in previous studies $[13,15]$. The majority $(78.6 \%)$ of CPA cases in our study occurred exclusively in the ipsilateral side of the resected lung. Furthermore, patients who underwent open thoracotomy had a risk of developing CPA that was more than nine times higher than that of those who received VATS; this supports the hypothesis that structural sequelae from lung surgery might be the main contributor in the development of CPA. Additionally, late-onset PPC was also associated with the development of CPA during long-term follow-up; this may be due to the development of further pulmonary damage from the complications themselves. Lastly, although it could not reach statistical significance, sublobar resection was associated with a lower risk of CPA, while bilobectomy was associated with a higher risk of CPA development, as compared with lobectomy. This also suggests that dead space formation, prolonged air-leak, or persistent bronchopleural fistula could be the possible mechanism in the pathogenesis of CPA [18-20].

Another possible explanation for the development of CPA after lung cancer surgery is the emergence of, to some degree, an impairment of the immune system. In our study, lower BMI, which is a surrogate marker of nutritional status, was an independent risk factor for CPA [21,22]. However, diabetes was not associated with the CPA development in our study [21]. Regarding the use of neoadjuvant and adjuvant therapies, chemotherapy alone was not significantly associated with the development of CPA in the multivariable model. This might be explained by the fact that, unlike in invasive aspergillosis, immunosuppression from cytotoxic agents is not the main pathogenic mechanism in CPA [23]. Rather, treatment with both chemotherapy and radiotherapy increased the risk of CPA, implying that structural damage from radiotherapy plays an important role and may function synergistically with chemotherapy. Similarly, a case report by Hiraki et al. described the development of aspergilloma in a cavity formed from the use of radiofrequency ablation to treat lung cancer [24]. On the other hand, patients who received neoadjuvant or adjuvant treatments have more advanced stages of NSCLC. Thus, these patients were more likely to have undergone additional cancer treatment afterward, which may further increase their vulnerability to these ubiquitous and often opportunistic respiratory pathogens.

Not surprisingly, a considerable number of patients had other underlying pulmonary conditions, aside from lung cancer surgery, such as COPD, asthma, previous pulmonary TB, and ILD. Although $\mathrm{COPD}$ and a history of TB were common comorbidities among patients with $\mathrm{CPA}$, there were no significant differences in the prevalence of these conditions between patients with and without CPA. Instead, our study showed that ILD was associated with an increased risk of developing CPA following lung cancer surgery, a finding that is consistent with a previous study [15]. Since the number of patients $(n=2)$ with ILD who also developed CPA was too small, it is difficult to draw a solid conclusion. However, both patients also had idiopathic pulmonary fibrosis (IPF) and neither of them was on steroid or immunosuppressive treatment. Interestingly, both of these patients developed dense consolidations 
around pre-existing bullae, which corresponds to the idea that expanded air space develops in the residual lung after lobectomy $[15,25]$.

Of note, the 5- and 10-year cumulative incidences of CPA in our study, which were $1.6 \%$ and $3.5 \%$, respectively, were lower than those of a previous study from Japan $(2.3 \%$ and $7.9 \%$, respectively) that was conducted exclusively on lobectomy cases [15]. Since the information regarding the risk factors identified in our study (BMI, surgical approach, PPC, and neoadjuvant and adjuvant therapy use) was not available from the Japanese study, it is difficult to explain what caused this difference. However, there were differences identified regarding the extent of the surgery as our study also included sublobar resection cases. Sublobar resection creates less dead space than lobectomies, which may partly explain the lower incidence of CPA in our study. Another discrepancy from the previous study is the side of the lungs where CPA developed. In our study, $12(21.4 \%)$ patients developed CPA on the contralateral side of the resected lung, whereas in the previous study all cases of CPA affected the same lung that was operated on [15]. Among these 12 patients, 8 had underlying structural abnormalities in the contralateral lung due to sequelae from previous TB $(n=3)$, bronchiectasis $(n=1), \operatorname{IPF}(n=1)$, emphysema $(n=1)$, cavitary changes secondary to cancer recurrence $(n=1)$, and subsequent wedge resection on the contralateral lung following cancer recurrence $(n=1)$. Many of these patients also had other risk factors including late-phase PPC $(n=3)$ and use of chemotherapy or chemoradiation therapy $(n=3)$. The remaining four patients who did not have underlying structural abnormalities suffered repeated episodes of pneumonia involving the contralateral lung after the surgery $(n=2)$ or during chemotherapy $(n=2)$. One patient also experienced late-phase PPC. Although the lack of information on the use of neoadjuvant/adjuvant therapies in the previous study prevents further comparison, a considerable number of patients (33.3\%) received these treatments in our study, which may have contributed to the development of CPA in the opposite lung.

Our study has several limitations. First, this is a retrospective cohort study from a single referral hospital that handles the largest volume of lung cancer surgeries in the nation. While this may explain the favorable 5-year survival rate in this cohort [26], it may also limit the generalizability of our results. Second, due to its retrospective nature, some patients with CPA might have not been identified since diagnostic tests were performed only when CPA was clinically suspected. Furthermore, the national health insurance system offers special benefits for cancer patients for 5 years starting from the time of diagnosis unless recurrence is documented; this is reflected in the duration of the patients' follow-up in our study. Indeed, about half $(47 \%)$ of the cases in the previous study developed more than 5 years after the lobectomy [15]. Thus, the incidence of CPA after lung cancer surgery may have been underestimated in our study. Third, data regarding detailed symptoms and their impact on the patient's quality of life were not available. Since both the respiratory and systemic symptoms of CPA can negatively impact the quality of life of patients [27], additional comprehensive studies are needed to investigate the effects of CPA on lung cancer survivors.

With the advent of more effective screening methods and improvements in treatment outcomes, more patients with NSCLC are surviving [28]. Among the various problems faced by lung cancer survivors, data regarding CPA remain sparse. Although the incidence of CPA after lung cancer surgery was relatively low at $3.5 \%$ at 10 years, our study found a steadily increasing trend during long-term follow-up. Increased awareness regarding this chronic sequela of lung cancer surgery is needed, especially in patients with risk factors.

Author Contributions: Study conception and design: S.H.S., B.-G.K., J.K. (Jiyeon Kang), Y.S.C., and B.-H.J. Data acquisition and analysis: S.H.S., B.-G.K., J.K. (Jiyoun Kang), S.-W.U., H.K., J.K. (Jhingook Kim), H.K.K., Y.M.S., Y.S.C., and B.-H.J. Data interpretation and manuscript writing: S.H.S., B.-G.K., Y.S.C., and B.-H.J. Revision of manuscript and contribution of intellectual content: All authors. All authors have read and agreed to the published version of the manuscript.

Funding: This research received no external funding.

Acknowledgments: The authors would like to thank the Statistics and Data Center, Research Institute for Future Medicine of Samsung Medical Center for the statistical analysis. The authors also would like to thank Jae Il Zo and Jong Ho Cho of the Department of Thoracic Surgery, and Kyungjong Lee of the Division of Pulmonary and 
Critical Care Medicine, Department of Medicine, Samsung Medical Center, Sungkyunkwan University School of Medicine, for providing the research data for this study.

Conflicts of Interest: The authors declare no conflict of interest.

\section{List of Abbreviations}

$\begin{array}{ll}\text { aHR } & \text { adjusted hazard ratio } \\ \text { BMI } & \text { body mass index } \\ \text { COPD } & \text { chronic obstructive pulmonary disease } \\ \text { CPA } & \text { chronic pulmonary aspergillosis } \\ \text { CI } & \text { confidence interval } \\ \text { CT } & \text { computed tomography } \\ \text { HR } & \text { hazard ratio } \\ \text { IQR } & \text { interquartile range } \\ \text { ILD } & \text { interstitial lung disease } \\ \text { IPF } & \text { idiopathic pulmonary fibrosis } \\ \text { NSCLC } & \text { non-small-cell lung cancer } \\ \text { OS } & \text { overall survival } \\ \text { PPC } & \text { postoperative pulmonary complication } \\ \text { TB } & \text { tuberculosis } \\ \text { VATS } & \text { video-assisted thoracoscopic surgery }\end{array}$

\section{References}

1. Howington, J.A.; Blum, M.G.; Chang, A.C.; Balekian, A.A.; Murthy, S.C. Treatment of stage I and II non-small cell lung cancer: Diagnosis and management of lung cancer, 3rd ed: American College of Chest Physicians evidence-based clinical practice guidelines. Chest 2013, 143, e278S-e313S. [CrossRef] [PubMed]

2. Henschke, C.I.; Yankelevitz, D.F.; Libby, D.M.; Pasmantier, M.W.; Smith, J.P.; Miettinen, O.S. Survival of patients with stage I lung cancer detected on CT screening. N. Engl. J. Med. 2006, 355, 1763-1771. [PubMed]

3. Aberle, D.R.; Adams, A.M.; Berg, C.D.; Black, W.C.; Clapp, J.D.; Fagerstrom, R.M.; Gareen, I.F.; Gatsonis, C.; Marcus, P.M.; Sicks, J.D. Reduced lung-cancer mortality with low-dose computed tomographic screening. N. Engl. J. Med. 2011, 365, 395-409. [PubMed]

4. Um, S.W.; Kim, H.K.; Jung, S.H.; Han, J.; Lee, K.J.; Park, H.Y.; Choi, Y.S.; Shim, Y.M.; Ahn, M.J.; Park, K.; et al. Endobronchial ultrasound versus mediastinoscopy for mediastinal nodal staging of non-small-cell lung cancer. J. Thorac. Oncol. 2015, 10, 331-337. [CrossRef] [PubMed]

5. Taioli, E.; Lee, D.S.; Lesser, M.; Flores, R. Long-term survival in video-assisted thoracoscopic lobectomy vs open lobectomy in lung-cancer patients: A meta-analysis. Eur. J. Cardiothorac. Surg. 2013, 44, 591-597. [CrossRef] [PubMed]

6. Kapadia, N.S.; Valle, L.F.; George, J.A.; Jagsi, R.; D’Amico, T.A.; Dexter, E.U.; Vigneau, F.D.; Kong, F.M. Patterns of Treatment and Outcomes for Definitive Therapy of Early Stage Non-Small Cell Lung Cancer. Ann. Thorac. Surg. 2017, 104, 1881-1888. [CrossRef] [PubMed]

7. Howlader, N.; Noone, A.M.; Krapcho, M.; Miller, D.; Brest, A.; Yu, M.; Ruhl, J.; Tatalovich, Z.; Mariotto, A.; Lewis, D.R.; et al. SEER Cancer Statistics Review, 1975-2016, National Cancer Institute; Bethesda: Montgomery, MD, USA, 2019; based on November 2018 SEER data submission, posted to the SEER web site, April 2019. Available online: https://seer.cancer.gov/csr/1975_2016/results_merged/sect_15_lung_bronchus.pdf (accessed on 2 November 2020).

8. Andalib, A.; Ramana-Kumar, A.V.; Bartlett, G.; Franco, E.L.; Ferri, L.E. Influence of postoperative infectious complications on long-term survival of lung cancer patients: A population-based cohort study. J. Thorac. Oncol. 2013, 8, 554-561. [CrossRef]

9. Agostini, P.; Cieslik, H.; Rathinam, S.; Bishay, E.; Kalkat, M.S.; Rajesh, P.B.; Steyn, R.S.; Singh, S.; Naidu, B. Postoperative pulmonary complications following thoracic surgery: Are there any modifiable risk factors? Thorax 2010, 65, 815-818. [CrossRef] 
10. Lugg, S.T.; Agostini, P.J.; Tikka, T.; Kerr, A.; Adams, K.; Bishay, E.; Kalkat, M.S.; Steyn, R.S.; Rajesh, P.B.; Thickett, D.R.; et al. Long-term impact of developing a postoperative pulmonary complication after lung surgery. Thorax 2016, 71, 171-176. [CrossRef]

11. Denning, D.W.; Cadranel, J.; Beigelman-Aubry, C.; Ader, F.; Chakrabarti, A.; Blot, S.; Ullmann, A.J.; Dimopoulos, G.; Lange, C. Chronic pulmonary aspergillosis: Rationale and clinical guidelines for diagnosis and management. Eur. Respir. J. 2016, 47, 45-68. [CrossRef]

12. Denning, D.W.; Pleuvry, A.; Cole, D.C. Global burden of chronic pulmonary aspergillosis as a sequel to pulmonary tuberculosis. Bull. World Health Organ. 2011, 89, 864-872. [CrossRef] [PubMed]

13. Smith, N.L.; Denning, D.W. Underlying conditions in chronic pulmonary aspergillosis including simple aspergilloma. Eur. Respir. J. 2011, 37, 865-872. [CrossRef] [PubMed]

14. Page, I.D.; Byanyima, R.; Hosmane, S.; Onyachi, N.; Opira, C.; Richardson, M.; Sawyer, R.; Sharman, A.; Denning, D.W. Chronic pulmonary aspergillosis commonly complicates treated pulmonary tuberculosis with residual cavitation. Eur. Respir. J. 2019, 53, e1801184. [CrossRef] [PubMed]

15. Tamura, A.; Suzuki, J.; Fukami, T.; Matsui, H.; Akagawa, S.; Ohta, K.; Hebisawa, A.; Takahashi, F. Chronic pulmonary aspergillosis as a sequel to lobectomy for lung cancer. Interact. Cardiovasc. Thorac. Surg. 2015, 21, 650-656. [CrossRef]

16. Edge, S.B.; Byrd, D.R.; Compton, C.C.; Fritz, A.G.; Greene, F.L.; Trotti, A. AJCC Cancer Staging Manual, 7th ed.; Springer: New York, NY, USA, 2010.

17. Miskovic, A.; Lumb, A.B. Postoperative pulmonary complications. Br. J. Anaesth. 2017, 118, 317-334. [CrossRef] [PubMed]

18. Jhun, B.W.; Jeon, K.; Eom, J.S.; Lee, J.H.; Suh, G.Y.; Kwon, O.J.; Koh, W.J. Clinical characteristics and treatment outcomes of chronic pulmonary aspergillosis. Med. Mycol. 2013, 51, 811-817. [CrossRef]

19. Hillerdal, G. Pulmonary aspergillus infection invading the pleura. Thorax 1981, 36, 745-751. [CrossRef]

20. Tokuishi, K.; Yamashita, S.; Hashimoto, T.; Moroga, T.; Miyawaki, M.; Chujo, M.; Yamamoto, S.; Kawahara, K.; Tokimatsu, I.; Kashima, K. Bronchial stump aspergillosis after stapled lobectomy for lung cancer. Ann. Thorac. Surg. 2012, 94, 1324-1326. [CrossRef] [PubMed]

21. Ohba, H.; Miwa, S.; Shirai, M.; Kanai, M.; Eifuku, T.; Suda, T.; Hayakawa, H.; Chida, K. Clinical characteristics and prognosis of chronic pulmonary aspergillosis. Respir. Med. 2012, 106, 724-729. [CrossRef]

22. Jhun, B.W.; Jung, W.J.; Hwang, N.Y.; Park, H.Y.; Jeon, K.; Kang, E.S.; Koh, W.J. Risk factors for the development of chronic pulmonary aspergillosis in patients with nontuberculous mycobacterial lung disease. PLOS ONE 2017, 12, e0188716. [CrossRef] [PubMed]

23. Yan, X.; Li, M.; Jiang, M.; Zou, L.Q.; Luo, F.; Jiang, Y. Clinical characteristics of 45 patients with invasive pulmonary aspergillosis: Retrospective analysis of 1711 lung cancer cases. Cancer 2009, 115, 5018-5025. [CrossRef]

24. Hiraki, T.; Gobara, H.; Mimura, H.; Sano, Y.; Takigawa, N.; Tanaka, T.; Kanazawa, S. Aspergilloma in a cavity formed after percutaneous radiofrequency ablation for lung cancer. J. Vasc. Interv. Radiol. 2009, 20, 1499-1500. [CrossRef]

25. Tanaka, H.; Matsumura, A.; Ohta, M.; Ikeda, N.; Kitahara, N.; Iuchi, K. Late sequelae of lobectomy for primary lung cancer: Fibrobullous changes in ipsilateral residual lobes. Eur. J. Cardiothorac. Surg. 2007, 32, 859-862. [CrossRef]

26. Bach, P.B.; Cramer, L.D.; Schrag, D.; Downey, R.J.; Gelfand, S.E.; Begg, C.B. The influence of hospital volume on survival after resection for lung cancer. N. Engl. J. Med. 2001, 345, 181-188. [CrossRef]

27. Al-Shair, K.; Muldoon, E.G.; Morris, J.; Atherton, G.T.; Kosmidis, C.; Denning, D.W. Characterisation of fatigue and its substantial impact on health status in a large cohort of patients with chronic pulmonary aspergillosis (CPA). Respir. Med. 2016, 114, 117-122. [CrossRef]

28. Vijayvergia, N.; Shah, P.C.; Denlinger, C.S. Survivorship in Non-Small Cell Lung Cancer: Challenges Faced and Steps Forward. J. Natl. Compr. Canc. Netw. 2015, 13, 1151-1161. [CrossRef]

Publisher's Note: MDPI stays neutral with regard to jurisdictional claims in published maps and institutional affiliations. 